\title{
Parectadial, a Monoterpenoid from the Defensive Spray of Parectatosoma mocquerysi Finot 1897
}

Aaron T. Dossey, ${ }^{\dagger}$ Spencer S. Walse, ${ }^{\dagger}$ Oskar V. Conle, ${ }^{\S}$ and Arthur S. Edison ${ }^{\dagger} \|_{*}$

Department of Biochemistry and Molecular Biology, University of Florida, Gainesville,

FL, 32610-0245; Center for Medical, Agricultural and Veterinary Entomology, USDA-

ARS, Gainesville, Florida 32604, Goldbachweg 24, 87538 Bolsterlang, Germany;

McKnight Brain Institute, University of Florida, 100 S. Newell Drive, Bld. 59, Rm. LG-

150, Gainesville, FL 32611; and National High Magnetic Field Laboratory, University of

\section{Florida}

* Correspondence should be addressed to: Prof. Arthur S. Edison, art@mbi.ufl.edu

${ }^{\dagger}$ Department of Biochemistry and Molecular Biology, University of Florida

$\$$ Center for Medical, Agricultural and Veterinary Entomology, USDA-ARS

$\S$ Bolsterlang, Germany

${ }^{\perp}$ McKnight Brain Institute, University of Florida

॥ National High Magnetic Field Laboratory, University of Florida

\section{Supporting Information}


Figure S1:

Gas Chromatograph (a) CI Mass Spectrum (b) and EI mass spectrum (c) of $P$. mocquerysi defensive spray MTBE extract.

a)
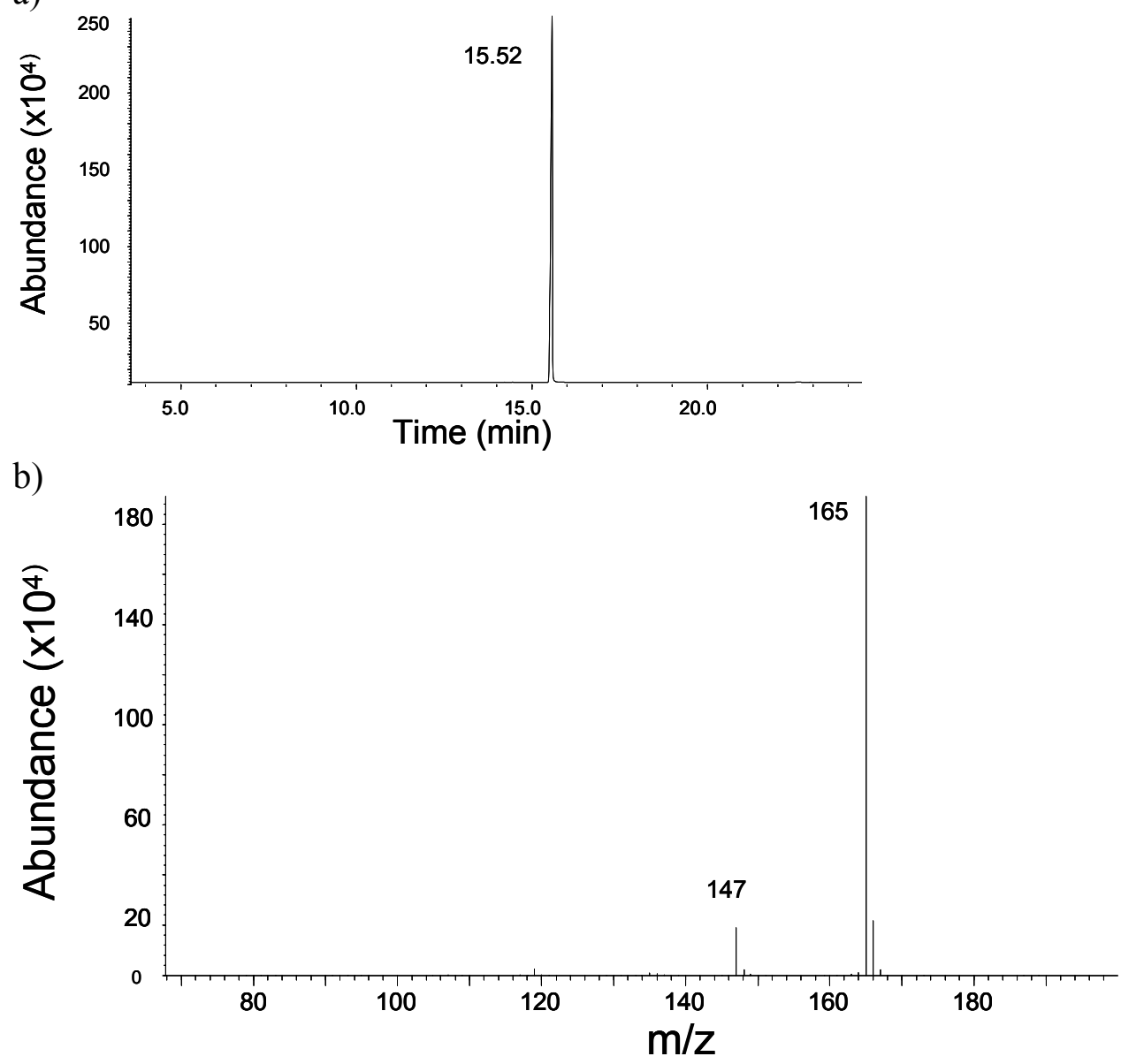

c)




Figure S2:

1D ${ }^{1} \mathrm{H}$ NMR for defensive secretion of $P$. mocquerysi (a) dissolved in $\mathrm{D}_{2} \mathrm{O}$ and (b) extracted into benzene- $\mathrm{d}_{6}$

a)

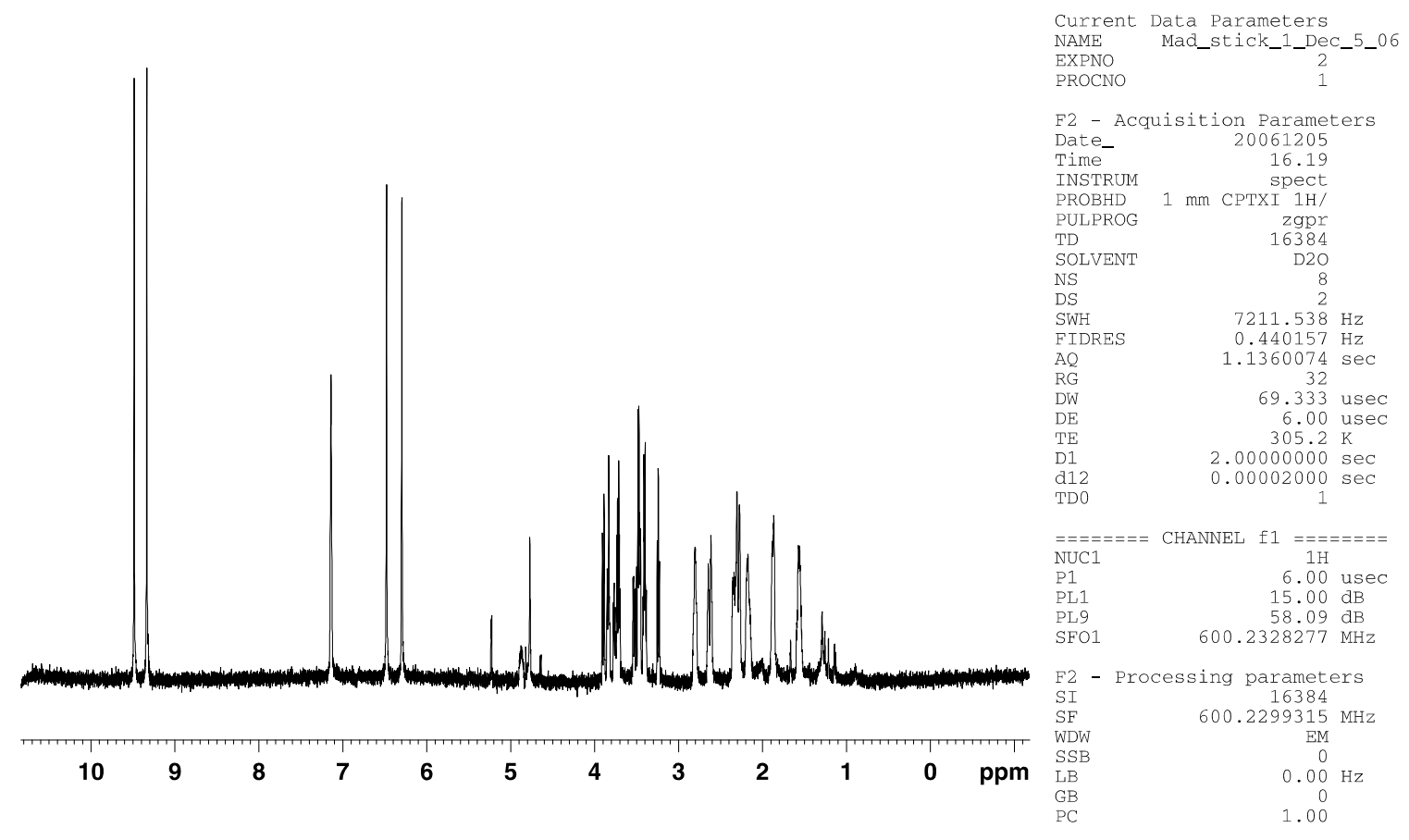


b)

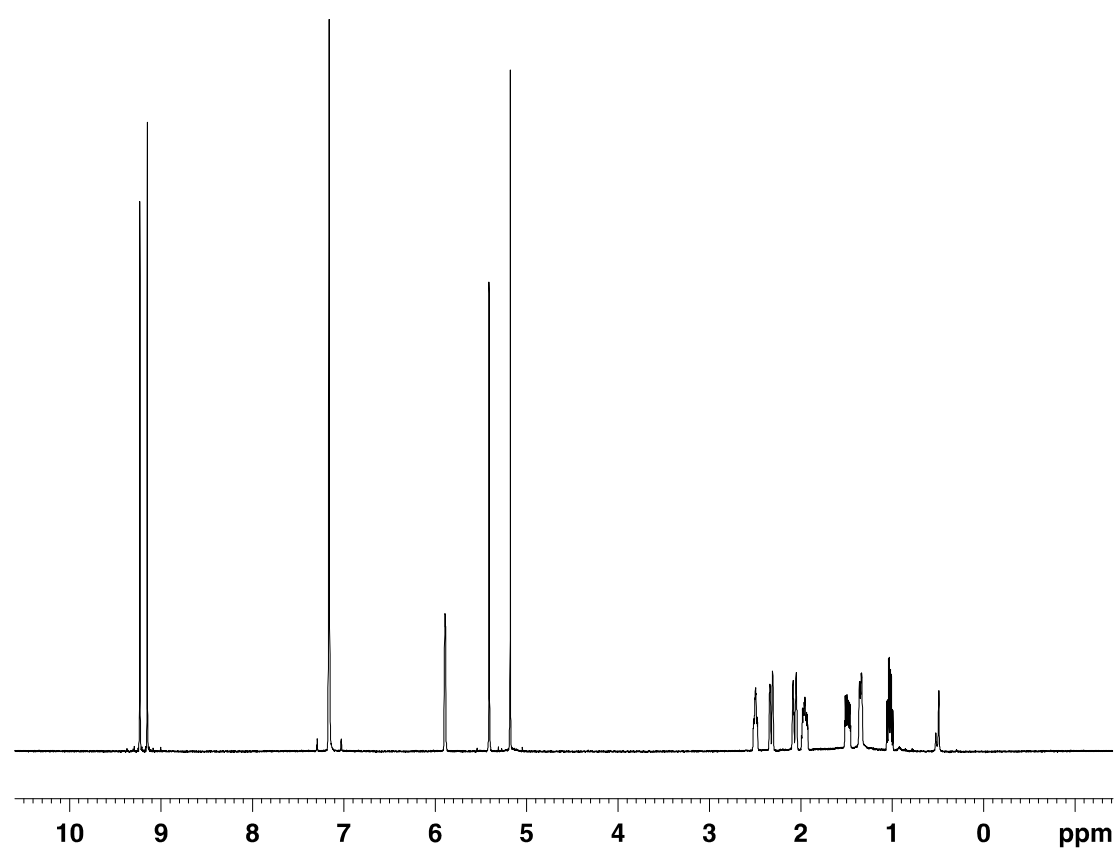

Current Data Parameters
NAME Mad_stick_1_Dec_5_06

5

F2 - Acquisition Parameters

Date Acquisition Para

Date__ 20061205

$\begin{array}{ll}\text { Time } & 19.02 \\ \text { INSTRUM } & \text { spect }\end{array}$

PROBHD $1 \mathrm{~mm} \mathrm{CPTXI} 1 \mathrm{H} /$

PULPROG $\quad \mathrm{zg}$

SOLVENT

NS

DS

FIDRES

$\mathrm{AQ}$

RG

DW

TE

D1

$====$
NUC1

P1

PL1

F2 - Processing parameters

SI Processing parameters

$\begin{array}{lr}\text { SI } & 600.2300717 \mathrm{MHz}\end{array}$

WDW

GB

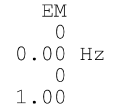


Figure S3:

2D NMR spectra for benzene- $\mathrm{d}_{6}$ extract of $P$. mocquerysi defensive spray: (a) COSY, (b) HMQC, (c) HMBC, and (d) expansion of aldehyde/vinyl region of NOESY.

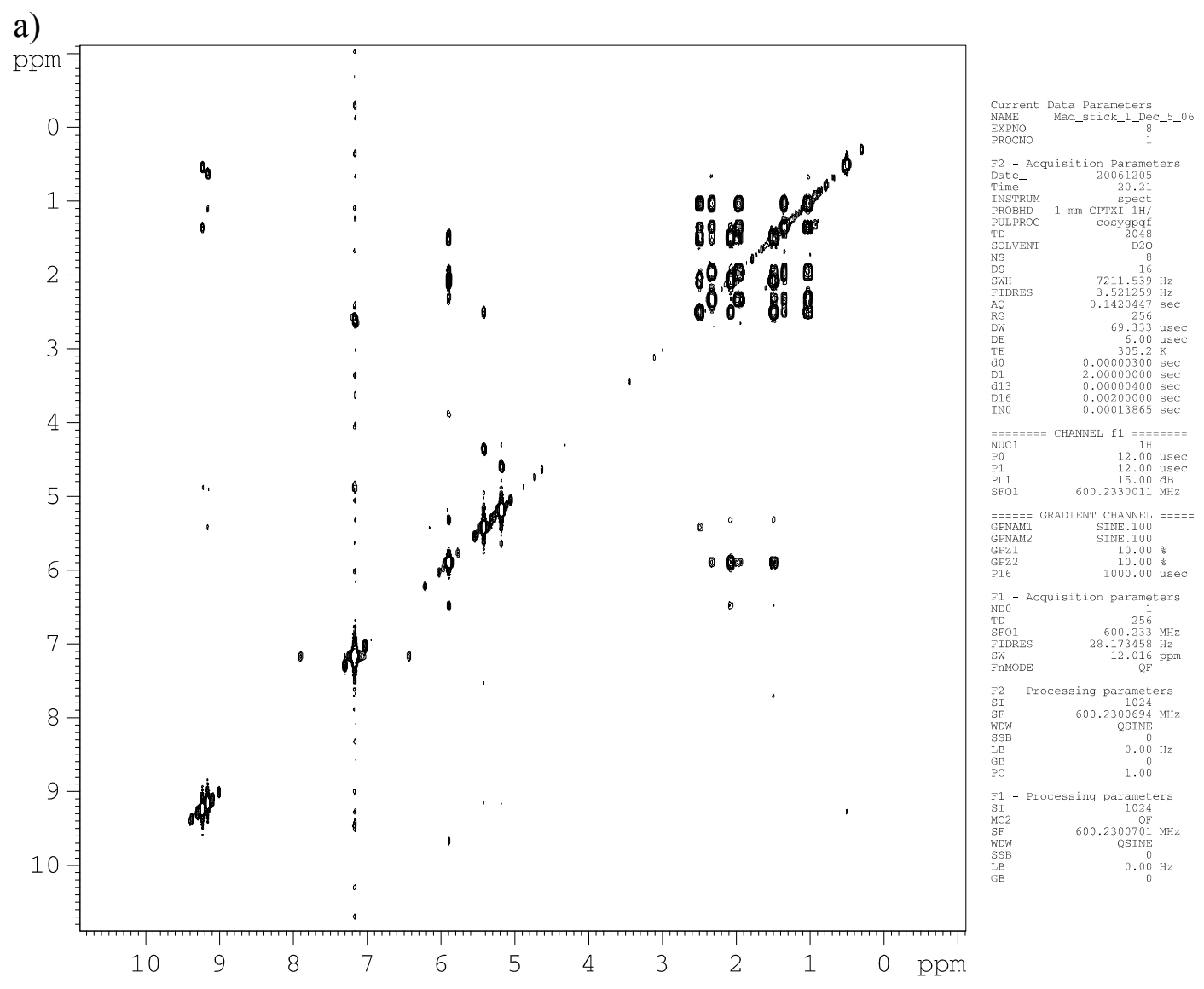


b)

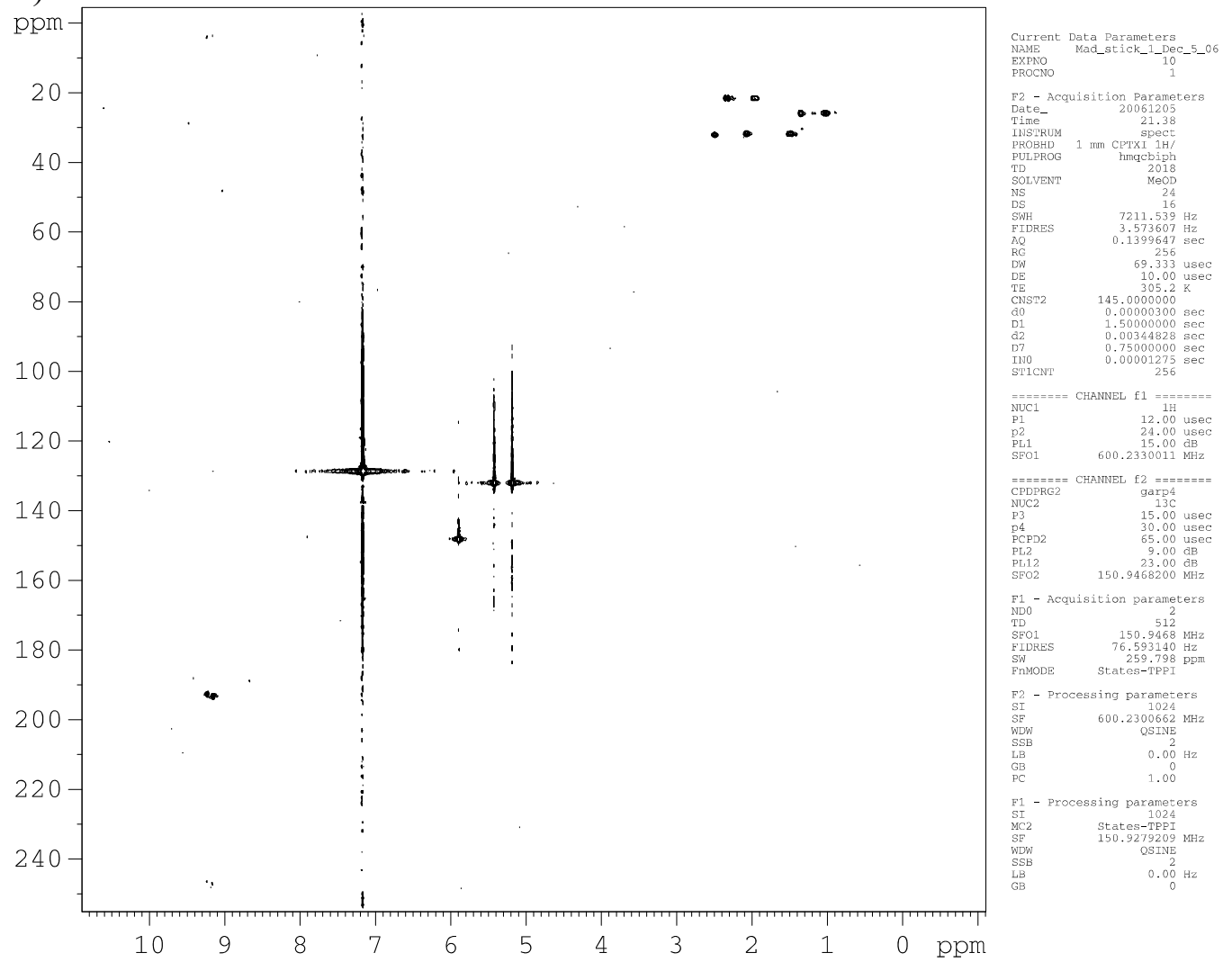


c)

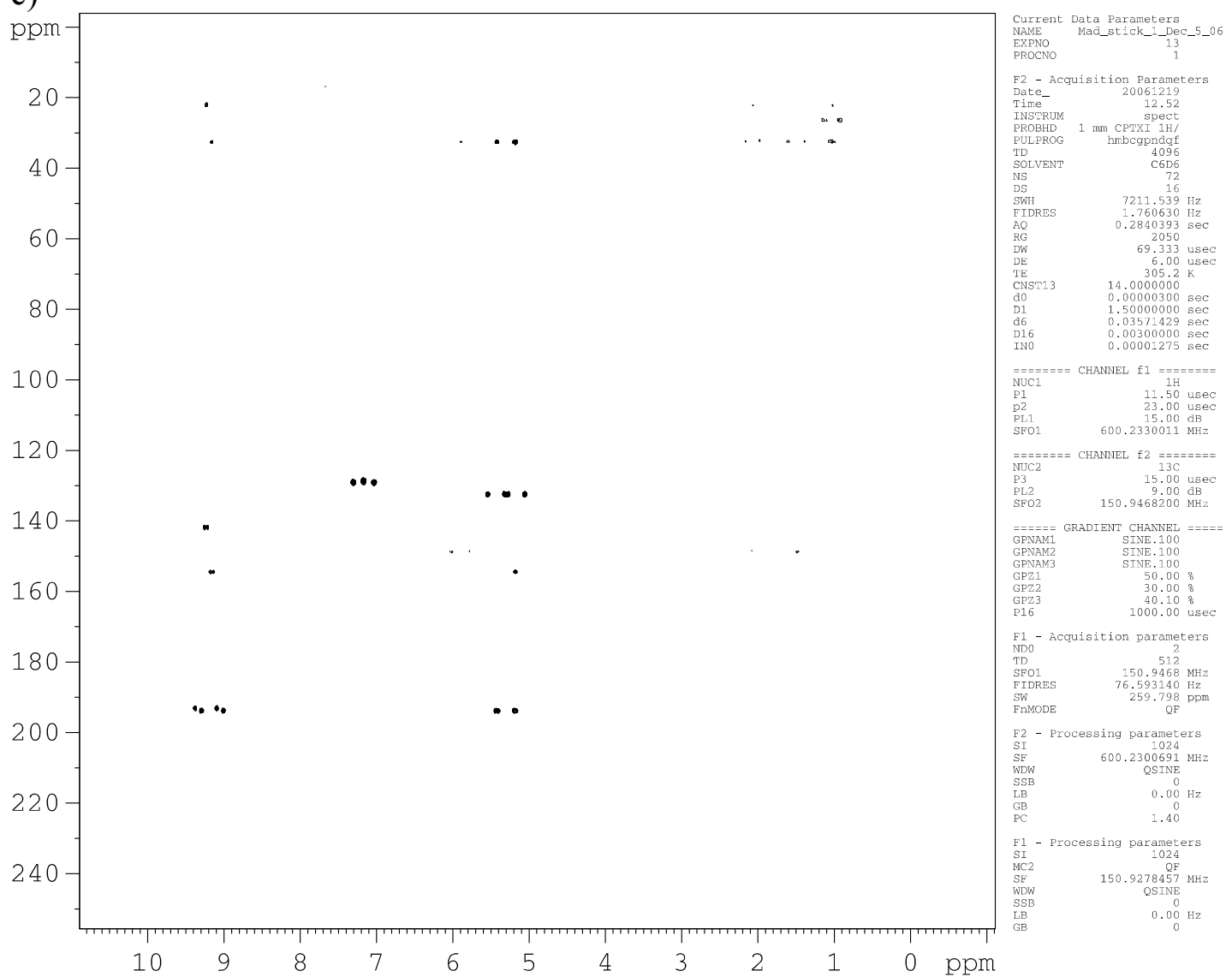




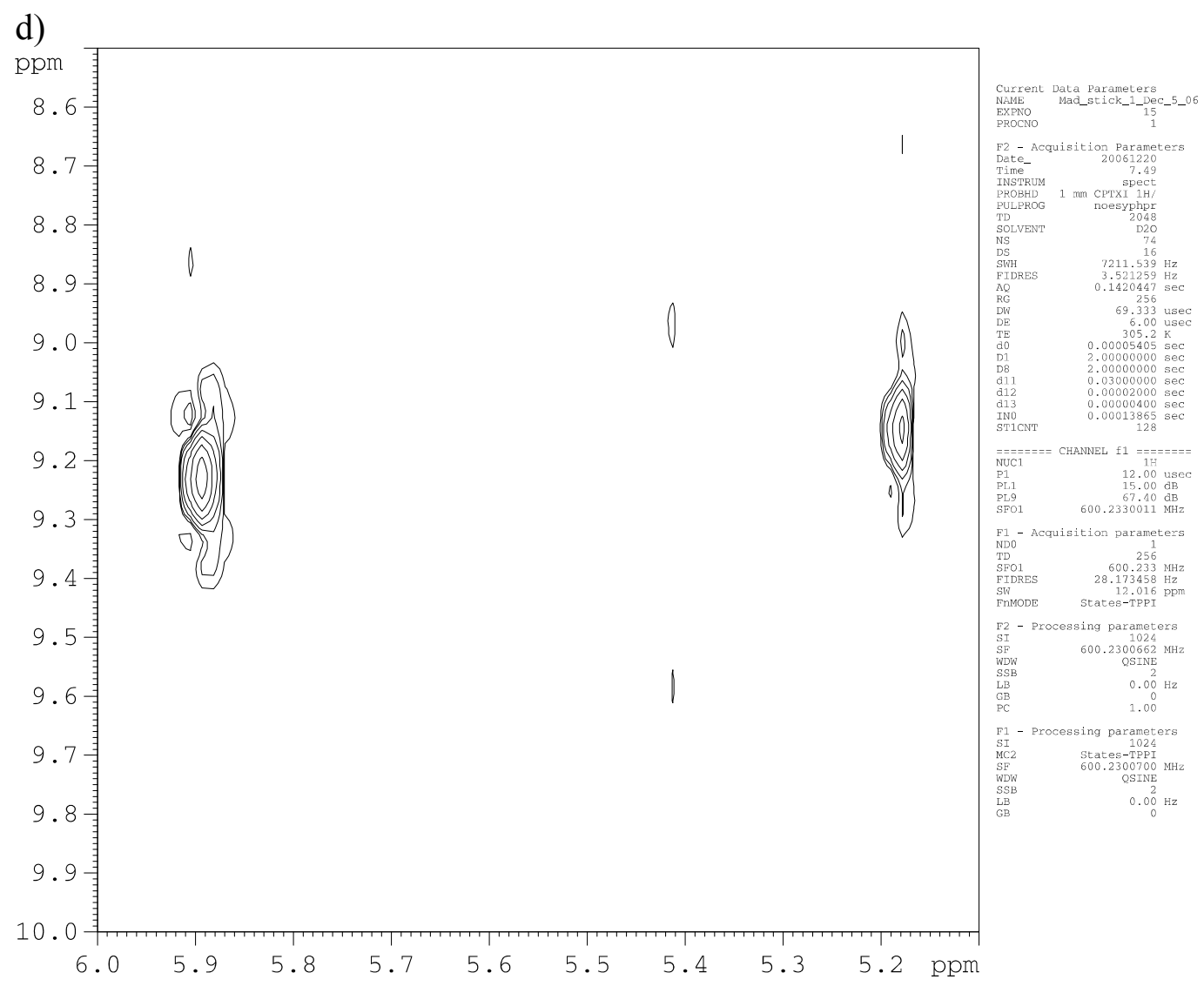


Figure S4:

1D ${ }^{1} \mathrm{H}$ and 2D NMR spectra of $S$-perillaldehyde dissolved in benzene-d 6 : (a) $1 \mathrm{D}{ }^{1} \mathrm{H}$ spectrum, (b) COSY, (c) HMQC, and (d) HMBC.

a)




b)

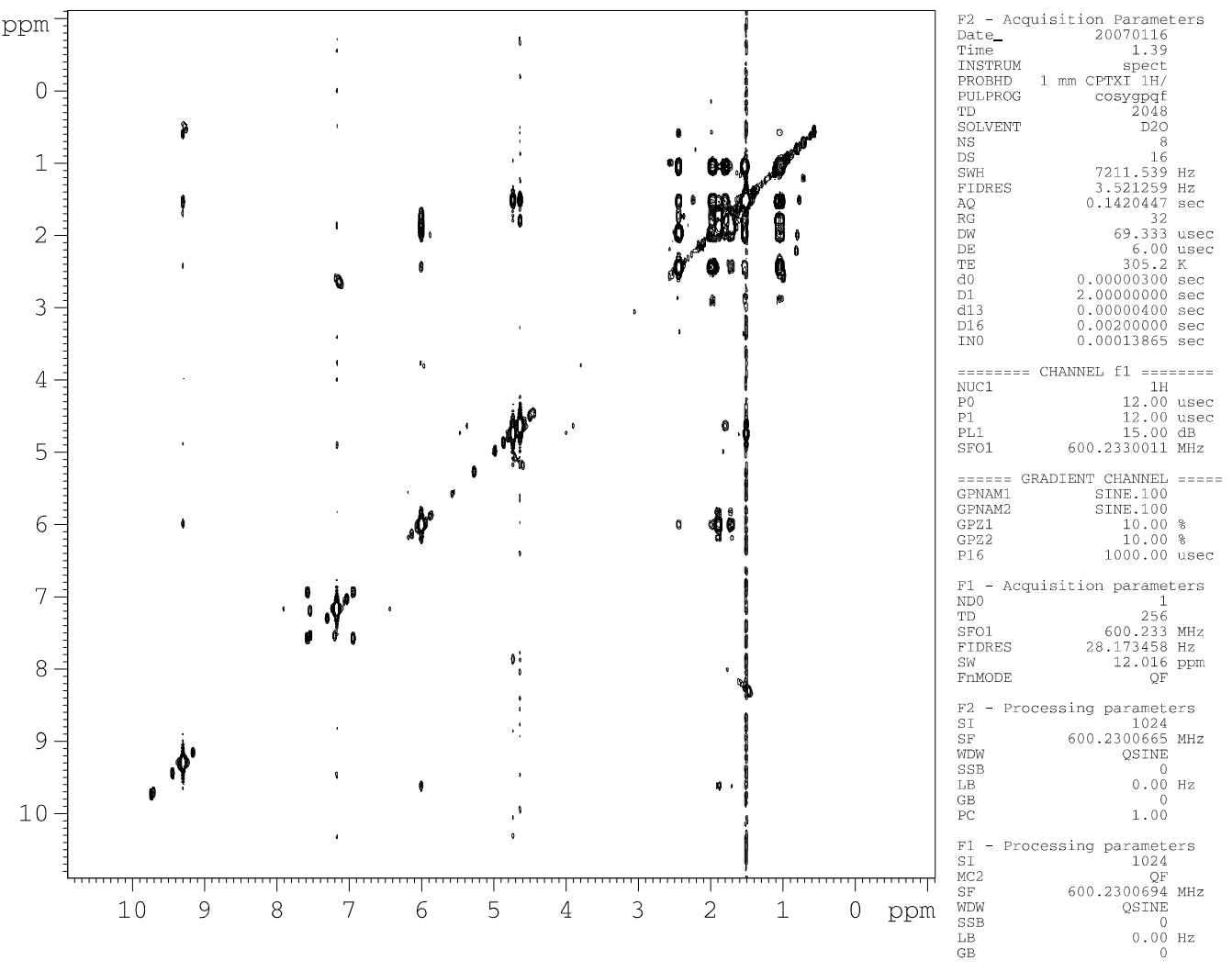


c)

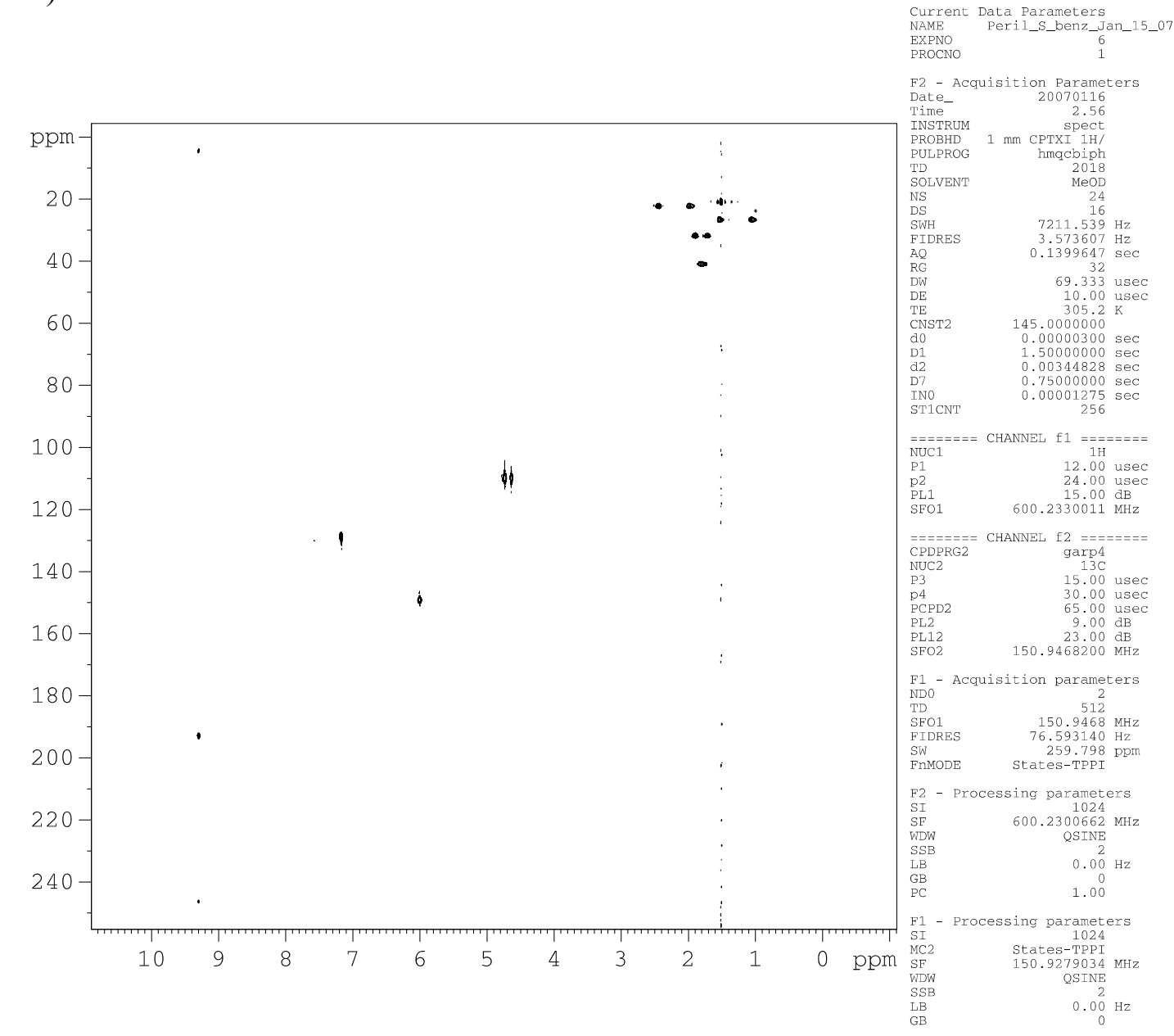


d)

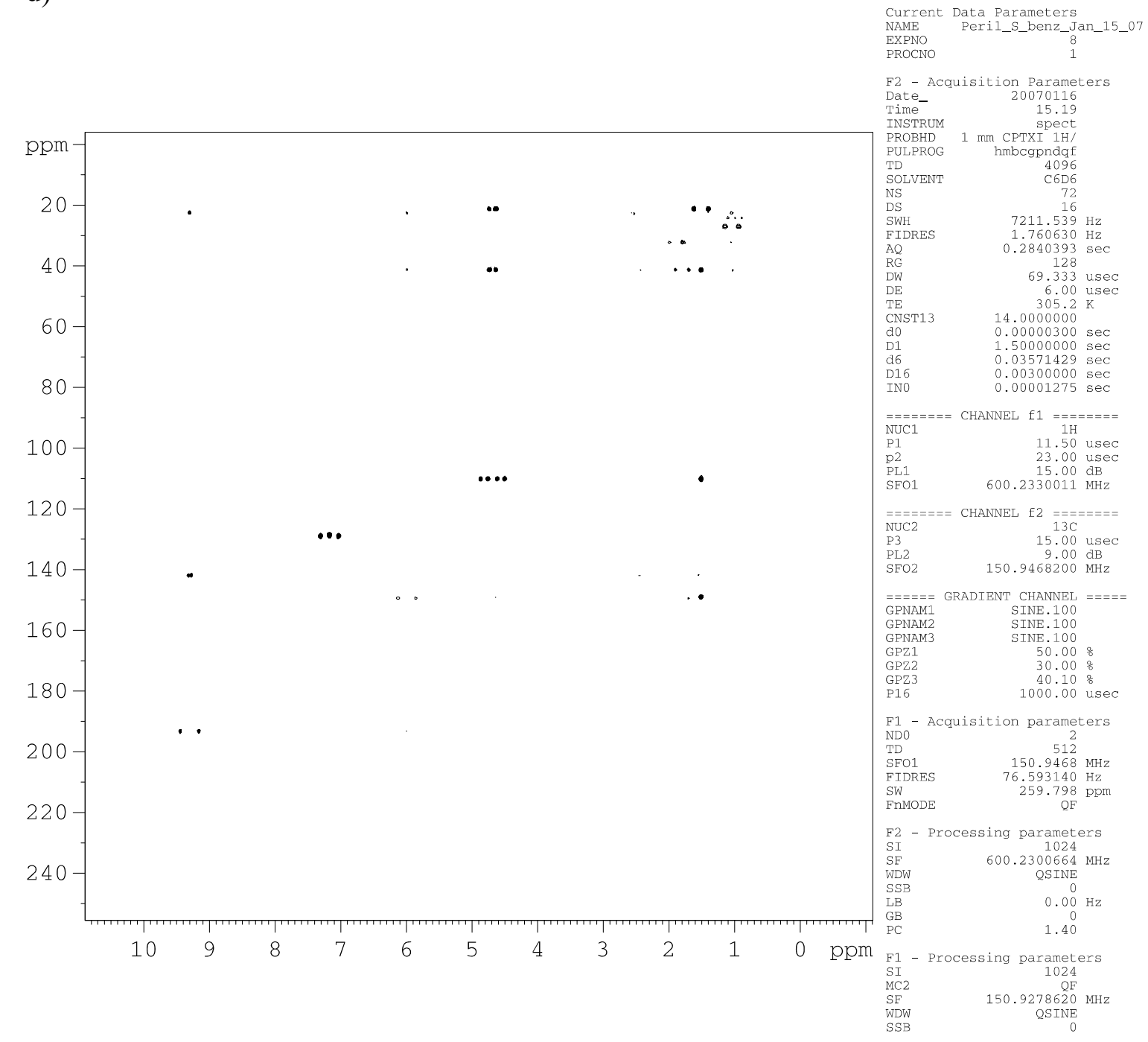




\section{Figure S5:}

1D ${ }^{1} \mathrm{H}$ spectra of (a) synthetic parectadial dissolved in benzene- $\mathrm{d}_{6}$ (top spectra) and benezene- $\mathrm{d}_{6}$ extract of $P$. mocquerysi defensive spray (bottom spectra) and expansions of (b) aldehyde, (c) vinyl, and (d) aliphatic regions.

a)
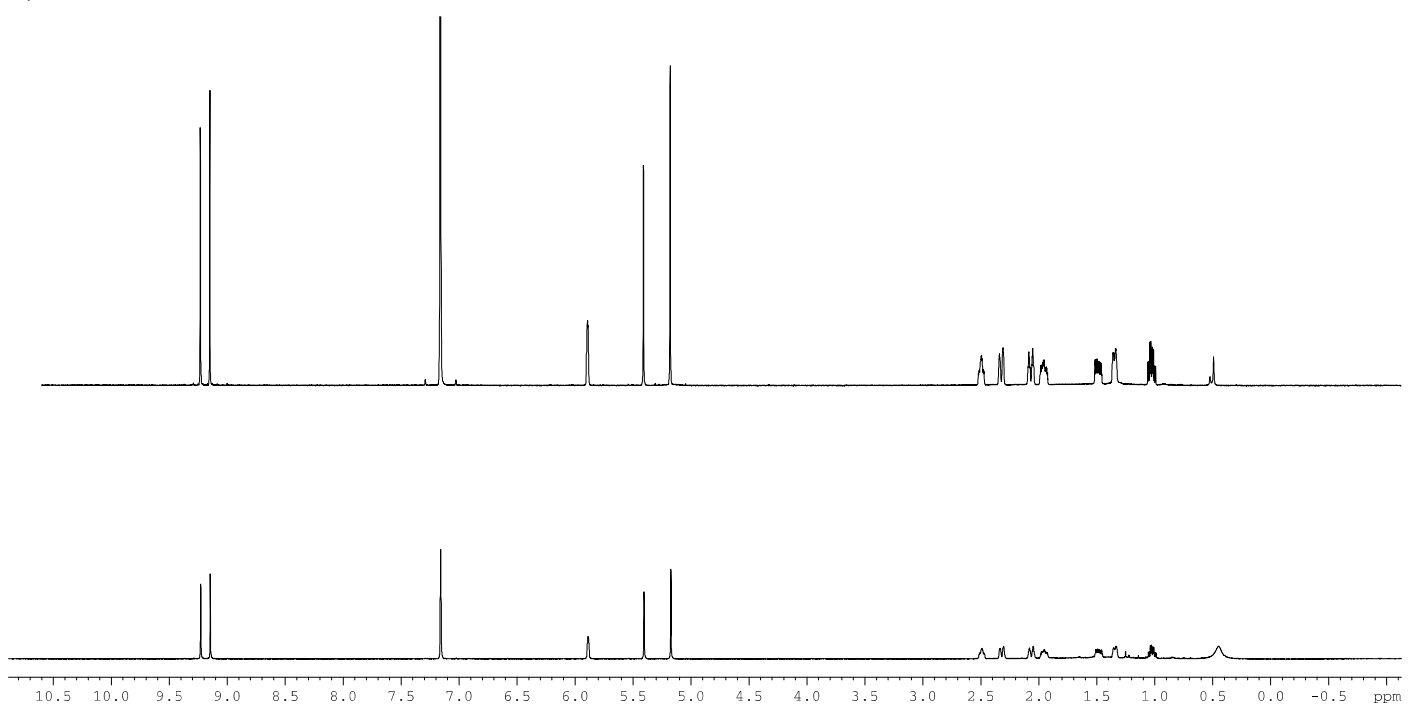

b)
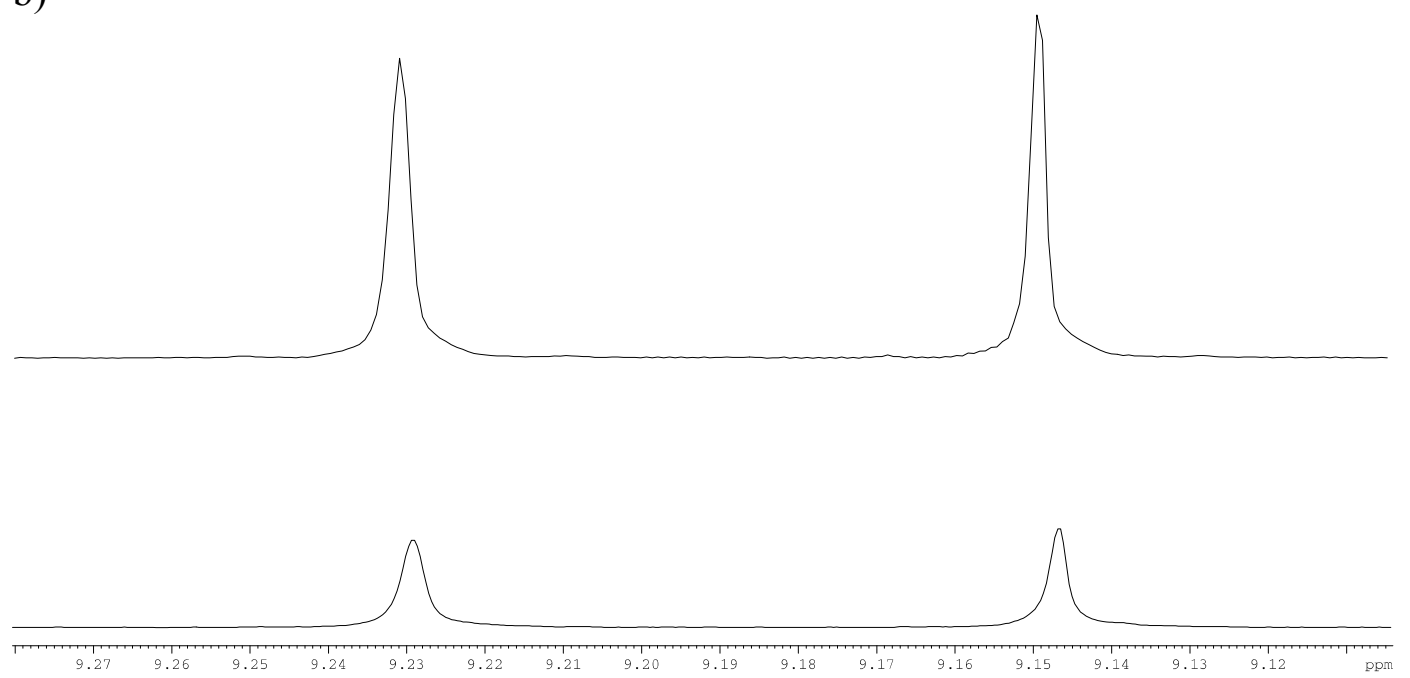
c)

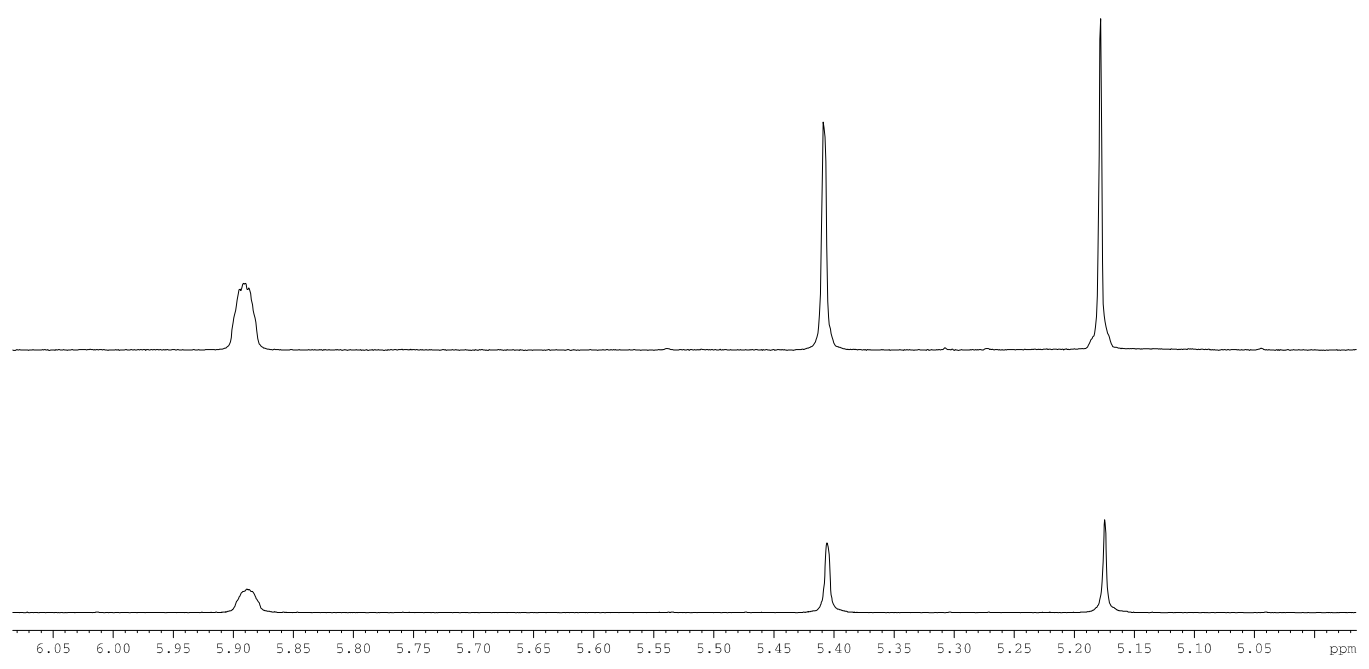

d)



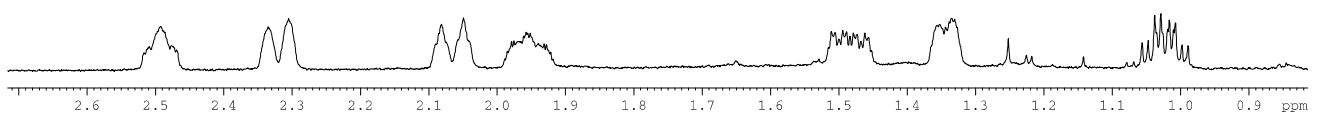


Figure S6:

Characterization of 4-perillyl alcohol:

The ${ }^{1} \mathrm{H}$ 1D NMR spectrum of the additional oxidation product (in benzene- $\mathrm{d}_{6}$ ) showed 8 resolved resonances that each integrated to one $\left(\delta_{\mathrm{H}} 9.28-1.89\right), 1$ singlet resonance (methyl) integrating to three $\left(\delta_{\mathrm{H}} 1.54\right)$, a complicated mixture of multiplets that collectively integrated to two $\left(\delta_{\mathrm{H}} 1.32-1.25\right)$, and a broad low frequency resonance that integrated to one $\left(\delta_{\mathrm{H}} 0.70\right)$, and a resonance likely to be water dissolved in benzene $\left(\delta_{\mathrm{H}}\right.$ $0.52)$. Of these resonances, one was in the aldehyde region $\left(\delta_{H} 9.28\right)$ and three in the vinyl region of the spectrum $\left(\delta_{\mathrm{H}} 4.72,4.84\right.$, and 5.89). In the COSY spectrum, strong correlations were observed between the vinyl at $5.89 \mathrm{ppm}$ and a pair of resonances $\left(\delta_{\mathrm{H}}\right.$ 1.89 and 2.00). Weaker COSY correlations were observed between the vinyl at $5.89 \mathrm{ppm}$ and another pair of resonances $\left(\delta_{\mathrm{H}} 2.23\right.$ and 2.31). These pairs of protons were observed to be part of methylenes and each pair on the same carbon atom based on the HMQC spectrum $\left(\delta_{\mathrm{C}} 18.8, \delta_{\mathrm{H}} 2.23\right.$, and $\left.\delta_{\mathrm{H}} 2.31\right)\left(\delta_{\mathrm{C}} 37.7, \delta_{\mathrm{H}} 1.89\right.$, and $\left.\delta_{\mathrm{H}} 2.00\right)$. Strong COSY correlations were also observed between the methylene resonances at 2.23 and 2.31 and a third pair of overlapped resonances $\left(\delta_{\mathrm{H}} 1.25-1.32\right)$, which were observed to be methylenes on the same carbon in the HMQC $\left(\delta_{\mathrm{C}} 31.0\right)$. Weaker COSY correlations were observed between the pair of resonances at 2.23 and $2.31 \mathrm{ppm}$ and those at 1.89 and $2.00 \mathrm{ppm}$, and between the pair of resonances at 1.89 and $2.00 \mathrm{ppm}$ and those from 1.25 to $1.32 \mathrm{ppm}$. These COSY and HMQC correlations taken together indicate that all observed methylenes are part of a ring structure. The methylenes with carbon resonances at 18.8 and $31.0 \mathrm{ppm}$ are also covalently connected. Additionally, the HMBC spectrum shows only one additional carbon resonance $\left(\delta_{\mathrm{C}} 140.6\right)$ with a strong correlation to the aldehyde resonance at $9.28 \mathrm{ppm}$ and weaker correlations to protons on all three of the identified methylenes $\left(\delta_{\mathrm{H}} 2.23,1.89\right.$, and 1.28). This carbon showed no correlation in the HMQC spectrum. These data indicate that this tertiary carbon is also involved in the ring system and covalently attached to the aldehyde group. A second tertiary carbon $\left(\delta_{\mathrm{C}} 70.1\right)$ showed strong HMBC correlations to the vinyl protons at 4.72 and $4.84 \mathrm{ppm}$ and the methyl group $\left(\delta_{\mathrm{C}} 18.5, \delta_{\mathrm{H}} 1.54\right)$ and weaker correlations to methylene resonances at 1.89 and $1.28 \mathrm{ppm}$, but no correlations in the HMQC spectrum. A third and final tertiary carbon $\left(\delta_{\mathrm{C}} 150.0\right)$ was observed with HMBC correlations only between a vinyl resonance at $4.84 \mathrm{ppm}$ and the methyl resonances at $1.54 \mathrm{ppm}$. The two vinyl resonances at 4.72 and $4.84 \mathrm{ppm}$ were attached to the same carbon atom $\left(\delta_{\mathrm{C}} 110.0\right)$ as observed in the HMQC spectrum. This carbon resonance also showed HMBC correlation to the methyl resonances at $1.54 \mathrm{ppm}$. Collectively, these data are consistent with structure 5. This is also the most parsimonious possibility of selenium dioxide oxidation of perillaldehyde in addition to parectadial. After searching the literature, it appeared that this new tertiary alcohol had not been previously characterized. Thus, we name it 4-perillyl alcohol. Stereochemical analyses of 4-perillyl alcohol were not performed as it would have been beyond the primary goal of the work to characterize $P$. mocquerysi defensive spray. 
1D ${ }^{1} \mathrm{H}$ and 2D NMR spectra of 4-perillyl alcohol dissolved in benzene- $\mathrm{d}_{6}$ : (a) $1 \mathrm{D}^{1} \mathrm{H}$ spectrum, (b) COSY, (c) HMQC, and (d) HMBC.

a)
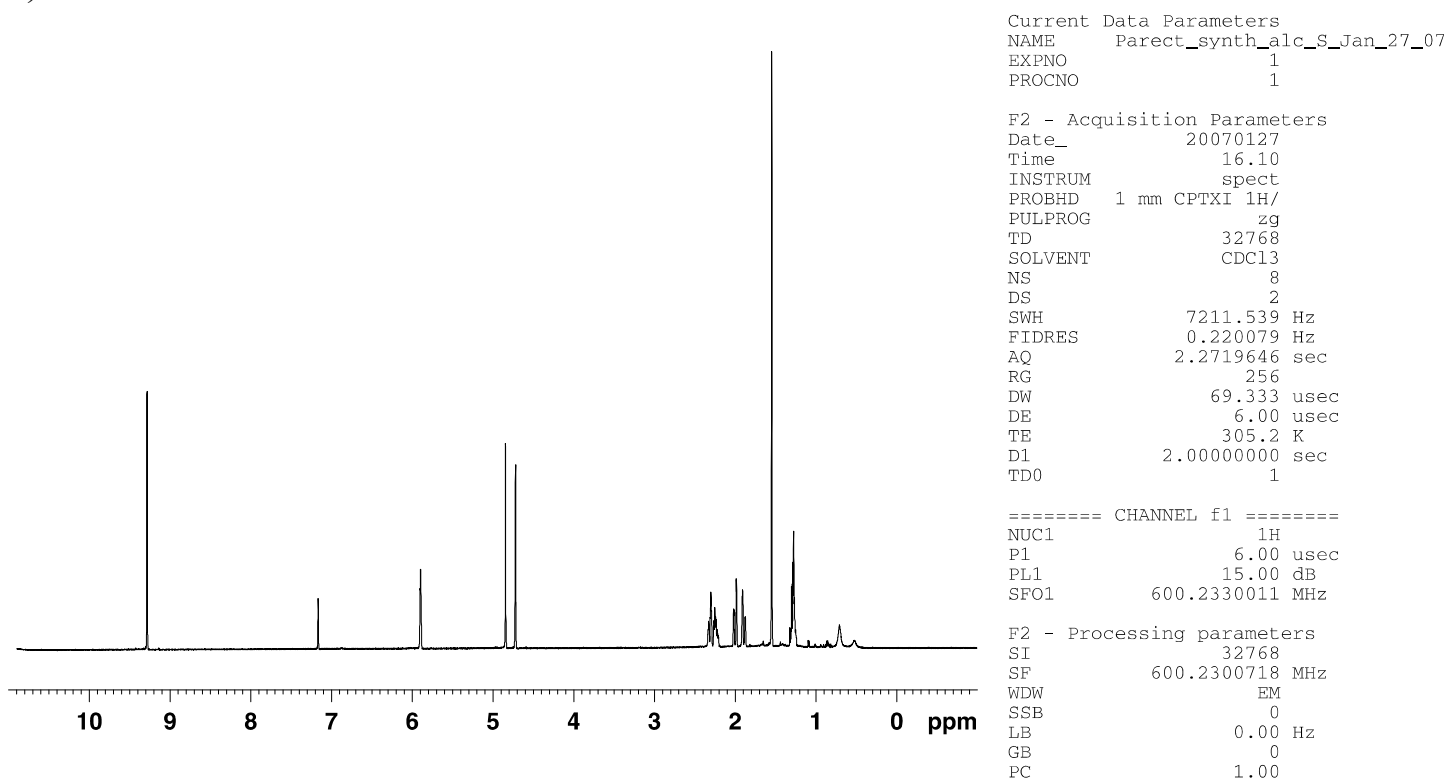
b)
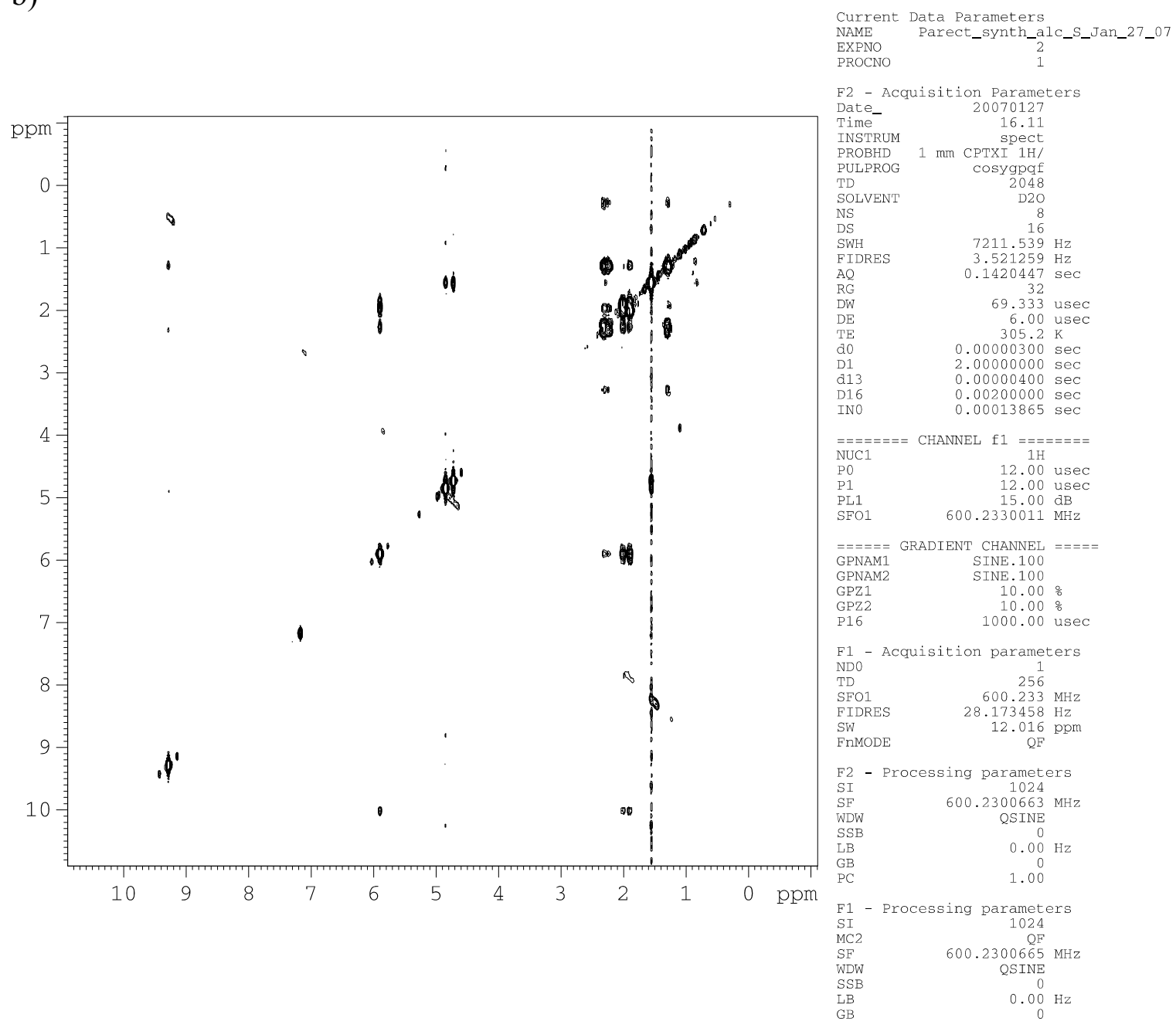
c)

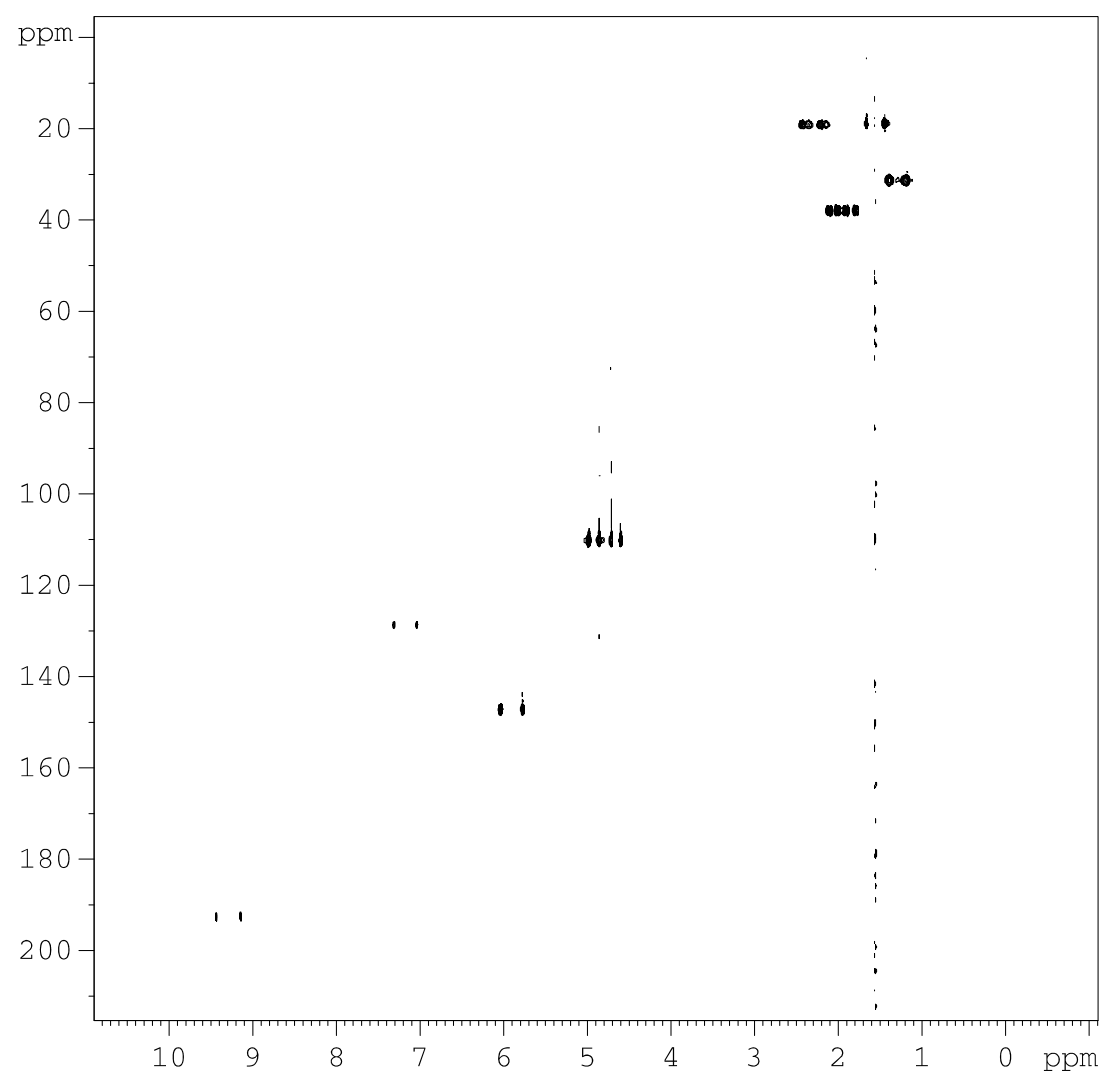

Current Data Parameters
NAME $\quad$ Parect_synth_alC_S_Jan_27_07 EXPNO
PROCNO

F2 - Acquisition Parameters

Date_ $\quad 20070128$

Time

PROBHD $1 \mathrm{~mm}$ СPTXI $1 \mathrm{H}$

PULPROG hmqcbindph

SOLVENT

NS

FIDRES

$7211.539 \mathrm{~Hz}$
$3.573607 \mathrm{~Hz}$
$0.1399647 \mathrm{sec}$

512
DW

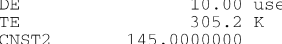

CNST2 $\quad 145.0000000$

$\begin{array}{ll}0.00000300 \mathrm{sec} \\ \text { D1 } & 1.50000000 \mathrm{sec}\end{array}$

$\begin{array}{ll}\text { D7 } & 0.75000000 \mathrm{sec} \\ \text { IN0 } & 0.00001505 \mathrm{sec}\end{array}$

T1CN

$==== \pm===$ CHANNEL $\mathrm{f} 1 \mathrm{=}=== \pm==$
NUC1
$1 \mathrm{H}$

$\begin{array}{ll}\mathrm{P} 1 & 12.00 \mathrm{usec} \\ \mathrm{p} 2 & 24.00 \mathrm{usec}\end{array}$

$\begin{array}{ll}\text { PL1 } & 15.00 \mathrm{~dB} \\ \text { SFO1 } & 600.2330011 \mathrm{MHz}\end{array}$

$=======$ CHANNEL f2 $========$
NUC2

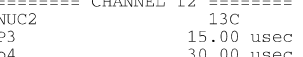

$\begin{array}{lr}\text { P4 } & 30.00 \text { usec } \\ \text { PL2 } & 9.000 \mathrm{~dB} \\ \text { FO2 } & 150.9438014 \mathrm{MHz}\end{array}$

F1 - Acquisition parameters

F1 - Acquisition parameters

$\begin{array}{lr}\text { TD } & 512 \\ \text { SFO1 } & 150.9438 \mathrm{MHz} \\ \text { FTDRES } & 64.887871 \mathrm{~Hz}\end{array}$

SW $\quad 220.099 \mathrm{ppm}$

F2 - Processing parameters

$\begin{array}{lr}\text { SI } & 1024 \\ \text { SF } & 600.2300662 \mathrm{MHz}\end{array}$

WDW $\quad$ QSINE

$\begin{array}{lc}\text { SSB } & 2 \\ \text { LB } & 0.00 \mathrm{~Hz}\end{array}$

PC

F1 - Processing parameters

$\begin{array}{lr}\text { SI } & 1024 \\ \text { MC2 } & \text { States-TPPI }\end{array}$

$\begin{array}{lc}\text { MC2 } & \text { States-TPPI } \\ \text { SF } & 150.9279150 \mathrm{MHz} \\ \text { WDW } & \text { QSINE }\end{array}$

LB $\quad 2$ 
d)

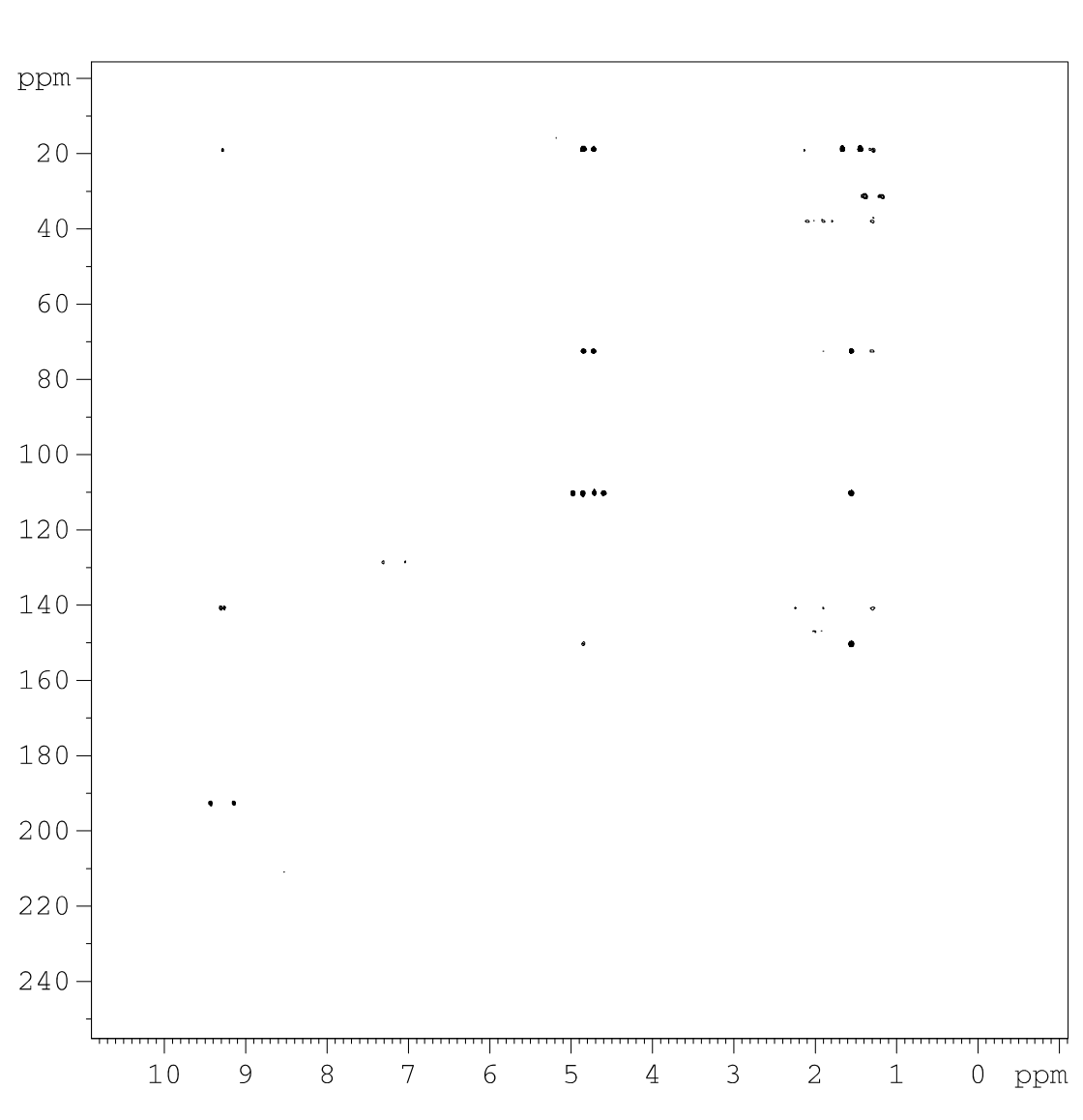

Current Data Parameters

Darect_aynth_alc_S_Jan_27_07 EXPNO

F2 - Acquisition Parameters
Date_ 20070128

$\begin{array}{lr}\text { Time } & 2007.46\end{array}$

PROBHD $1 \mathrm{~mm}$ CPTXI $1 \mathrm{H} /$

PULPROG hmbcgpndqf

4096

NS

$\begin{array}{r}16 \\ 7211.539 \\ \hline\end{array}$

FIDRES $\quad 1.760630 \mathrm{~Hz}$

$0.2840393 \mathrm{sec}$

$\begin{array}{rr}\mathrm{DW} & 69.333 \text { usec } \\ \mathrm{DE} & 6.00 \mathrm{usec}\end{array}$

$6.05 .2 \mathrm{~K}$
$0.00000300 \mathrm{sec}$

CNST13 $\quad 14.0000000$

$10.00000300 \mathrm{sec}$

16 $\quad 0.03571429 \mathrm{sec}$

$\begin{array}{ll}\text { D16 } & 0.00300000 \mathrm{sec} \\ \text { INO } & 0.00001275 \mathrm{sec}\end{array}$

$=======$ CHANNEL $f 1$ $=======$

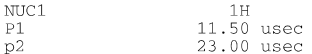

P21 $15.00 \mathrm{~dB}$

SFO1 600.2330011 MHz

$=======$ CHANNEL $\mathrm{f} 2=======$
NUC2 $13 \mathrm{C}$
15.00 usec

$\begin{array}{lr}\text { P3 } & 15.00 \text { usec } \\ \text { PL2 } & 9.00 \mathrm{~dB}\end{array}$

SFO2 $150.9468200 \mathrm{MHZ}$

$=====$ GRADIENT CHANNEL $=====$ SINE. 100
GPNAM1

GPNAM3 $\quad$ SINE. 100

$\begin{array}{ll}\text { GPZ1 } & 50.00 \% \\ \text { GPZ2 } & 30.00 \%\end{array}$

$\begin{array}{lr}\text { GPZ3 } & 40.10 \% \\ \text { P16 } & 1000.00 \mathrm{usec}\end{array}$

F1 - Acquisition parameters

$\begin{array}{lr}\text { ND0 } & 2 \\ \text { TD } & 512\end{array}$

$\begin{array}{lr}\text { SFO1 } & 150.9468 \mathrm{MHz} \\ \text { FIDRES } & 76.593140 \mathrm{~Hz}\end{array}$

$\begin{array}{ll}\text { SW } & 259.798 \mathrm{ppr}\end{array}$

F2 - Processing parameters
SI
1024

$\begin{array}{lc}\text { SE } & 600.2300663 \mathrm{MHz} \\ \text { WDW } & \text { QSINE }\end{array}$

$\begin{array}{lr}\mathrm{SSB} & 0 \\ \mathrm{LB} & 0.00 \mathrm{~Hz}\end{array}$

PC 1.40

F1 - Processing parameters

$\begin{array}{lc}\text { SI } & 1024 \\ \text { MC2 } & \text { QF } \\ \text { SF } & 150.9279167 \mathrm{MHz} \\ \text { WDW } & \text { QSINE } \\ \text { SSB } & 0 \\ \text { LB } & 0.00 \mathrm{~Hz}\end{array}$ 
Figure S7:

Ultraviolet-Visual (UV-Vis) wavelength spectrum of synthetic $S$-parectadial in ethanol.

\section{$0.72 \mathrm{mM}$ in ethanol}

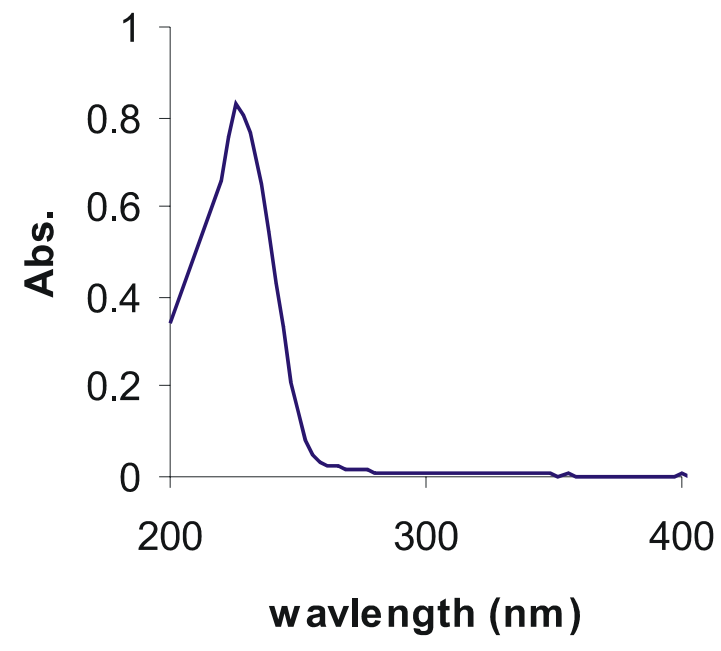

